\title{
Aiming to increase birth weight: a randomised trial of pre-pregnancy information, advice and counselling in inner-urban Melbourne
} Judith Lumley*1 and Lisa Donohue ${ }^{2,3}$

\author{
Address: ${ }^{1}$ Mother and Child Health Research, La Trobe University, 251 Faraday St Carlton, Victoria 3053, Melbourne, Australia, ${ }^{2}$ Key Centre for \\ Women's Health in Society, University of Melbourne, Level 1, 305 Cardigan St, Carlton, Victoria 3053, Melbourne, Australia and ${ }^{3}$ Western \\ Hospital, Gordon St Footscray, Victoria 3011, Melbourne, Australia \\ Email: Judith Lumley* - j.lumley@latrobe.edu.au; Lisa Donohue - ldonohue@bluep.com \\ * Corresponding author
}

Published: 10 December 2006

BMC Public Health 2006, 6:299 doi:10.1 186/147/-2458-6-299

This article is available from: http://www.biomedcentral.com/147I-2458/6/299

(c) 2006 Lumley and Donohue; licensee BioMed Central Ltd.

This is an Open Access article distributed under the terms of the Creative Commons Attribution License (http://creativecommons.org/licenses/by/2.0), which permits unrestricted use, distribution, and reproduction in any medium, provided the original work is properly cited.
Received: 23 June 2006

Accepted: 10 December 2006

\begin{abstract}
Background: In the 1980s there was substantial interest in early pregnancy and pre-pregnancy interventions to increase birth weight and reduce preterm birth. We developed an inter-pregnancy intervention, implemented in a randomised controlled trial, to be provided by midwives at home soon after women's first birth.

Methods: $\mathrm{MCH}$ nurses invited women to take part during their home visit to new mothers. Women's contact details, with their permission, were passed to the study midwife. She had a randomisation schedule to which women's names were added before she met the women or their partners. All women recruited had a home visit from the study midwife with a discussion of their first pregnancy, labour and birth and the postpartum experience. Women in the intervention arm received in addition a pre-pregnancy intervention with discussion of social, health or lifestyle problems, preparation and timing for pregnancy, family history, rubella immunisation, referrals for health problems, and a reminder card. The primary outcome was defined as a birth weight difference in the second birth of $100 \mathrm{~g}$ (one-sided) in favour of the intervention. Additional data collected were gestational age, perinatal deaths and birth defects. Analyses used EPI-INFO and STATA.
\end{abstract}

Results: Intervention and comparison groups were comparable on socioeconomic factors, prior reproductive history and first birth outcomes. Infant birth weight in the second birth was lower (-97.4 g,)) among infants in the intervention arm. There were no significant differences between intervention and comparison arms in the proportion of women having a preterm birth, an infant with low birthweight, or an infant with a birth weight $<10^{\text {th }}$ percentile. There were more adverse outcomes in the intervention arm: ten births $<32$ weeks), compared with one in standard care, and more infants with a birth weight $<2000$ g, 16 compared with two in standard care

Conclusion: As the primary outcome was envisaged to be either improved birth weight or no effect, the study was not designed to identify the alternative outcome with confidence. Despite widespread support for pre-pregnancy interventions to improve maternal and perinatal health, this first randomised controlled trial of a multi-component intervention provided at home, did not have a beneficial outcome. 


\section{Background}

At the time this project was initiated (1980-85) there was substantial interest in the idea of pre-pregnancy - or preconception - counselling and care. Pre-pregnancy care was discussed in three contexts. The first was routine advice, counselling and care around rubella immunisation, nutrition, smoking, alcohol consumption, and exercise for all women, prior to conception and thus prior to antenatal care $[1,2]$ The second was provision of advice and counselling on specific issues for women perceived to have increased risks of an adverse pregnancy outcome; women with recurrent miscarriage, a prior perinatal death, a prior infant with low birthweight or an infant with a major birth defect [3]. The third was care of women with known risks to the fetus or themselves from maternal health problems such as diabetes, epilepsy, heart disease, renal disease, or from indicated treatment [4].

The rationale, then and now, was that many factors affecting fetal health and survival, or maternal health, are present well before the first antenatal visit, often before conception, limiting options for effective intervention in pregnancy [5]. Other considerations were that assistance and support for modifying behaviours such as smoking might be more effective prior to pregnancy, given the increased anxiety that may occur in early pregnancy. Before assessment of gestational age by ultrasound scanning became common, there were also concerns that a 'natural' cycle and a reliable date for the last menstrual period needed to be re-established before conception; thus women were advised to replace hormonal contraception or intrauterine devices with barrier methods for several months before trying to conceive.

\section{Pre-pregnancy Information and Counselling Service (PPIS)} The setting in which the trial was planned was a newly established pre-pregnancy service (PPIS) in inner urban Melbourne [6]. It was initiated by two obstetricians from a University Department of Obstetrics and Gynaecology, in association with a Community Health Centre, and funded within a new, national, community health programme. The primary role of the PPIS was to provide a 'universal' walk-in service locally, and a secondary school health education component. It also accepted referrals and provided a telephone information service. One fulltime, experienced, midwife, subsequently increased to 1.5 positions, staffed the PPIS, with support from the first author. The PPIS self-referral and telephone service attracted in the main well educated and socially advantaged women, who were not living in the locality. This finding, together with the policy that evaluation was to have a key role in services funded by the new community health program, contributed to the development of the pre-pregnancy intervention trial.
Objectives of the PPIS trial

1. To recruit women into a randomised trial of pre-pregnancy advice/counselling in a community setting where mothers were at higher risk of a poor outcome. The three local areas had substantial numbers of recent migrants, refugees, single parents, families with a low income and families in public housing

2. To assess the effectiveness of the intervention in terms of the birthweight of the second child, as the most sensitive single indicator of fetal wellbeing.

3. To incorporate the intervention, including data collection and follow-up, into the routine work of community health nurses/midwives and Maternal and Child Health Nurses (MCHN) to be able to assess the feasibility of implementing the intervention more widely if it were effective.

Local MCHNs were key partners in the trial. They provided a universal service funded by local government and State government, from postnatal hospital discharge, at that time more than five days after birth for the majority of women, to school entry. In Victoria, all births are notified by the hospital of birth to the MCH Centre closest to the woman's residence, with a statutory home visit by the MCHN in the first week after hospital discharge. Over 95\% of women attend the MCH Centre in the first six months after birth [8]. Consultations were held with the Director of Maternal and Child Health (Health Department of Victoria), the Regional Infant Welfare Advisors, Infant Welfare staff in municipalities close to the Community Health Centre, the Administrator and Board of Management of the Community Health Centre, and the Central Health Interpreter Service, in the planning phase. At these meetings we discussed the trial rationale, the intervention, planned recruitment and follow-up, seeking input on how these could be incorporated into the standard working of each of the services. There was strong support for the proposed trial across all those consulted.

\section{Methods \\ Design}

The study design was a randomised controlled trial, with individual randomisation. It was designed to be able to identify a mean birth weight difference of $\geq 100 \mathrm{~g}$ in the intervention arm. There was no Data Monitoring Committee and no stopping rules were defined.

\section{Participants and recruitment procedures}

All women attending local $\mathrm{MCH}$ Centres with their first child were eligible for inclusion in the trial. Each MCHN discussed the project briefly with all eligible women and asked permission to give the PPIS midwife their contact 
details. The PPIS midwife collected women's names and addresses weekly from the $\mathrm{MCH}$ nurses, and recorded whether an interpreter would be needed, and for what language. Women's names were then entered into the trial logbook where the sequence of allocations (derived from random number tables by the first author and utilising balanced block randomisation in blocks of two, four or six) was already listed. Thus allocation occurred before the PPIS midwife had met the woman. The PPIS midwife contacted women whose details had been provided and arranged a home visit to confirm participation. There was a Central Health Interpreter Service in Melbourne at that time making it possible to book an interpreter for a specific language for the home visit, so that a significant proportion of immigrant women could be included.

Recruitment began in May 1982 and ended in July 1991. The timing of recruitment was in the early months after the first birth, to ensure that the women's own health was recognised as a key factor, as it has been in more recent interventions [7]. Follow-up continued to the end of 1994.

\section{The intervention}

Comparison group

All women recruited received a home visit from the PPIS midwife with a discussion of their first pregnancy, labour and birth and the postpartum experience. Any questions asked by the women were answered.

\section{Intervention group}

Women randomised to receive the intervention received a pre-pregnancy health intervention that consisted of:

1. Identification of any current social, health or lifestyle problems.

2. Discussion of timing, planning and preparation for the next pregnancy

3. Offers of referral for any specific problem identified (e.g. to a dietician, relaxation group, physiotherapist, family planning clinic, general practitioner) all available at the Community Health Centre or nearby, or at a local hospital clinic; linkage with appropriate community resources (e.g. language-specific play-group) and networks.

4. Taking a family/genetic history and arranging a referral if necessary.

5. Arranging for rubella immunisation if not immune
6. Discussion of the points summarised on a WAIT, STOP, and GO reminder card. The card was headed Signs to follow before pregnancy, and designed to mimic traffic lights:

\section{WAIT (Orange)}

- For 3 months after using the pill or loop

- For 3 months after German measles vaccination

- Until you really want another child

\section{$>$ STOP (Red)}

- Cigarettes

- Alcohol

- Other over the counter drugs and medications

$>$ Go (Green)

- To the doctor when you have missed two periods

- Regularly for antenatal checks

- Ring us if you have any questions or problems

The card included the name and address of the PPIS and the telephone number.

The commonest issues raised by women in the intervention arm at this time were choice of contraceptive method ( $\mathrm{n}=274)$, the 'ideal' interval between children (262), smoking (202), rubella (199), diet (177), operative birth (175), alcohol (172), breastfeeding (170), sex since the birth (166), caring for the baby (121), the decision to have another child (102) and postnatal depression (76).

\section{Sample size, primary outcome and secondary outcomes}

The study was designed to identify a difference of $\geq 100 \mathrm{~g}$ in the primary outcome - the mean birth weight of the second children, in favour of the intervention arm of the trial ( $\alpha=0.05, \beta=0.80$. one-sided), calculated as 394 in each arm. Loss to follow-up was predicted to be at least $20 \%$, making the total recruitment goal 950 women [9] Secondary outcomes were gestational age at birth, preterm birth grouped as 20-27 weeks, 28-31 weeks, and 32-36 weeks; low birth weight $(<2,500 \mathrm{~g})$, perinatal deaths and birth defects. Birth weights less than the sex-specific $10^{\text {th }}$ percentile were added later. All twins were included in the birth weight analysis [10]. They were excluded from birth weight $<10^{\text {th }}$ percentile as the standards for this categorisation were derived from singleton births only [11]. 


\section{Data collection and analysis}

Information about the previous pregnancy and birth was hand written on A5 cards at the first home visit by the PPIS midwives, and updated at later contacts. Where possible, follow-up of the subsequent birth took place at a planned home visit, but telephone and - letters were also used, especially when women had moved outside the local area. Most participants provided details for at least one close relative as a secondary contact. When these processes were inadequate, follow-up data on the outcome of the second pregnancy and birth were sought from the referring MCHN and, if the woman had moved to another part of the State, from the MCHN in the new area. Transfer of the data to computer did not occur until 1995. EPI INFO [12] was used for data checking and cleaning.

Data analysis was carried out using EPI-INFO and STATA version 8 [13]. Characteristics of the parents and the first child were described and tabulated. Intervention and comparison groups were compared in terms of the first and second child's birth weight (mean and standard deviation), the proportions of infants with low birth weight, preterm birth and in preterm subgroups, and among singletons the proportions with a birth weight below the 10 th percentile for gestational age and sex. Given the very small number of infants who died or had birth anomalies these are described in full but not formally compared. One analysis that was not pre-specified but prompted by study findings compared the time interval from the first birth to the conception of the second infant in the two arms of the trial.

\section{Results}

Table 1 shows the flow of participants through the trial: 1688 were approached, 109 refused (65 in the intervention arm, 44 in standard care), and 1579 agreed to take part. Many of those who refused were defined as de facto refusals since they had agreed to take part, and provided contact details, but did not keep appointments, were not at home for up to three planned visits, behaved in a threatening way - or their partner did - or refused entry to the PPIS midwife. When participating women had their first visit a further $11 \%$ were found to be ineligible (see Table $1)$. A further 84 had already moved out of the area the time of the first attempted contact, 63 were already pregnant and 29 already had two or more children, something not known to the $\mathrm{MCH}$ service. More women from the intervention arm (157) than in the standard care arm (128) were lost or ineligible, leaving 1403 active participants. Women subsequently lost to the study were those who decided not to have another child ( $n=31)$, usually for reasons of severe parental ill health; those who had not had a second pregnancy by 1995 (222), and 364 who were lost to follow-up. Fewer women were lost to followup from the intervention arm (173) than from the standard care arm (191) at this stage making the final participants 392 in the intervention arm and 394 in the comparison arm.

Table I: Recruitment, refusals, eligibility, and later study losses

\begin{tabular}{lcc}
\hline Recruitment, randomisation and losses & Intervention & Comparison \\
\hline Women approached & 842 & 846 \\
Refused & -65 & -44 \\
Agreed to participation, recruited and randomised & 777 & 802 \\
Ineligible post randomisation & -44 & -40 \\
Moved before Ist contact & -33 & -30 \\
Pregnant before Ist contact & -15 & -14
\end{tabular}

Ineligible and/or refused prior to trial

Eligible and consenting to participation

Subsequent loss to the study

Decision not to have another child

No $2^{\text {nd }}$ pregnancy by end 1994

Lost to follow-up
Total -92 Total -84

$\begin{array}{cc}685 & 718 \\ -12 & -19 \\ -108 & -114 \\ -173 & -191\end{array}$

Ineligible or lost to follow-up of those eligible and consenting

Study completion
Total -293

Total -324 
The socio-demographic and past reproductive history characteristics of the study families are summarised in Table 2. The population recruited was typical of innerurban Melbourne at that time, in terms of the proportion of women born outside Australia (more than a third), the proportion born in a country where English was not the primary language (a quarter), and the other countries of birth most commonly represented (Vietnam and Greece). The occupations of fathers were similar in the two arms [14], as were the specific Local Government Areas of the families' residence at recruitment. Prior reproductive problems and mode of delivery at the first birth were also similar in intervention and comparison groups. The two groups did not differ in the duration of breastfeeding, the type of contraception used, or the interval between the intervention and the birth of the second child.

Table 3 summarises the perinatal outcomes of the first births. The mean birth weights differed by only $39 \mathrm{~g}$ in intervention and comparison arms and the standard deviation was the same in both arms. The proportion with an infant of low birth weight $(<2,500 \mathrm{~g})$ was similar in the two arms, (5\% and $4 \%)$. The proportion of infants with a birth weight below the $10^{\text {th }}$ percentile using sex-specific tables was also similar (16\% and 13\%). The mean gestational age was identical in the two arms. There was a small difference in rates of preterm birth, $6.5 \%$ in the intervention and $4.6 \%$ in the comparison arm There were no differences in very preterm births ( $<32$ weeks gestation). There were no perinatal deaths and no infants with major birth anomalies among the participants' first births. The infants included four sets of twins, one in the intervention arm and three in the comparison arm.

Table 4 summarises the perinatal outcomes post-intervention. At the second birth the primary outcome measure was a significant difference in mean birth weight, but the outcome was not in the predicted direction. Babies in the intervention arm were lighter by $97 \mathrm{~g}$. There were no significant differences in mean gestational age, though the standard error was larger in the intervention arm. The proportion with a birth weight below the $10^{\text {th }}$ percentile using sex-specific tables did not differ significantly in the two arms, being $11 \%$ in the intervention arm and $8 \%$ in the comparison arms. There were more infants with birth weights below $1500 \mathrm{~g}$ and below $2000 \mathrm{~g}$ in the intervention arm, and a marked difference in births $<32$ weeks gestation, with ten births in the intervention arm and one in the comparison arm The second births included four sets of twins, two in the intervention and two in the comparison arms.

There were seven known perinatal death among the second births, four associated with birth defects and three infants born extremely preterm, including one set of
Table 2: Characteristics of the participants

\begin{tabular}{|c|c|c|c|c|}
\hline \multirow[b]{2}{*}{ Maternal age } & \multicolumn{2}{|c|}{ Intervention: $\mathrm{N}=392$} & \multicolumn{2}{|c|}{ Comparison: $\mathrm{N}=394$} \\
\hline & $\mathrm{N}$ & $\%$ & $\mathrm{~N}$ & $\%$ \\
\hline$<20$ & 10 & 2.6 & 18 & 4.6 \\
\hline $20-24$ & 81 & 20.9 & 70 & 17.9 \\
\hline $25-29$ & 127 & 32.4 & 144 & 36.9 \\
\hline $30-34$ & 135 & 34.2 & 129 & 33.1 \\
\hline $35-39$ & 36 & 9.2 & 27 & 6.9 \\
\hline$\geq 40$ & 0 & - & 2 & 0.5 \\
\hline Missing data & 3 & - & 4 & - \\
\hline \multicolumn{5}{|c|}{ Region of birth (Mother) } \\
\hline Australia & 254 & 64.5 & 279 & 70.8 \\
\hline New Zealand/UK & 23 & 5.9 & 13 & 3.3 \\
\hline Europe & 28 & 7.1 & 24 & 6.1 \\
\hline Asia/Middle East & 75 & 19.1 & 71 & 18.0 \\
\hline Africa & 6 & 1.5 & 4 & 1.0 \\
\hline America & 5 & 1.3 & 3 & 0.8 \\
\hline Missing data & 1 & - & 0 & - \\
\hline \multicolumn{5}{|l|}{ Occupation (Father) } \\
\hline Professional & 16 & 4.1 & 14 & 3.6 \\
\hline Proprietor/Manager & 24 & 6.1 & 15 & 3.8 \\
\hline Office and sales worker & 89 & 22.7 & 111 & 28.2 \\
\hline Farmer & 87 & 22.2 & 83 & 21.1 \\
\hline Skilled worker & 60 & 15.3 & 53 & 13.5 \\
\hline Semiskilled worker & 72 & 18.4 & 79 & 20.0 \\
\hline Unskilled worker & 42 & 10.7 & 39 & 9.9 \\
\hline Missing data & 2 & - & 0 & - \\
\hline \multicolumn{5}{|c|}{ Local Government area } \\
\hline A & 181 & 46.1 & 190 & 48.2 \\
\hline B & 120 & 30.6 & 112 & 28.4 \\
\hline C & 66 & 16.8 & 72 & 18.3 \\
\hline Other & 25 & 5.6 & 20 & 5.1 \\
\hline \multicolumn{5}{|l|}{ Prior problems } \\
\hline Infertility & 31 & 7.9 & 36 & 9.1 \\
\hline Prior miscarriage $\geq 1$ & 37 & 9.4 & 43 & 10.9 \\
\hline Prior termination $\geq 1$ & 43 & 11.0 & 36 & 9.1 \\
\hline Ist birth unplanned & 105 & 26.8 & 115 & 29.2 \\
\hline Ist birth unwanted & 11 & 2.8 & 7 & 1.8 \\
\hline \multicolumn{5}{|l|}{ First birth } \\
\hline Spontaneous vaginal* & 180 & 46.1 & 206 & 52.3 \\
\hline Forceps & 118 & 30.0 & 115 & 29.2 \\
\hline Vacuum & 3 & 0.8 & 2 & 0.5 \\
\hline Elective caesarean & 15 & 3.6 & 9 & 2.3 \\
\hline Emergency caesarean & 48 & 12.3 & 40 & 10.2 \\
\hline Missing data & 28 & 7.2 & 22 & 5.6 \\
\hline
\end{tabular}

* includes 4 vaginal breech births in each arm

twins. The perinatal mortality was $8.9 / 1000$ births. The perinatal mortality in the State of Victoria for 1983-92 was 8.8/1000 births [15]. Infants known to have birth anomalies included two with anencephaly, one with major multiple malformations (not specified), one with multiple heart defects and an absent right kidney, one with a ventricular septal defect, one with aniridia, one with Hirschsprung's disease and one with a fetal heart defect, not otherwise described, and congenital heart block. Five infants with a birth anomaly were in the intervention arm, two in the comparison arm, a combined prevalence of 8.8/1000. In 1983-94 the overall prevalence of birth anomalies in singletons in Victoria, includ- 
Table 3: Perinatal outcomes of the I $^{\text {st }}$ birth (pre-intervention)

\begin{tabular}{|c|c|c|c|}
\hline & Intervention $\mathrm{N}=392$ & Comparison $\mathrm{N}=394$ & \\
\hline \multicolumn{4}{|l|}{ Birth weight } \\
\hline Mean (SD), g & $3296(509)$ & $3335(504)$ & Difference $-39 \mathrm{~g}$, \\
\hline Missing data & (3) & (2) & \\
\hline Birth weight $<10^{\text {th }}$ percentile* & $43(11 \%)$ & $32(8 \%)$ & OR (exact) I.39 [0.84,2.33] \\
\hline \multicolumn{4}{|l|}{ Low Birth weight } \\
\hline$<1000 \mathrm{~g}$ & 0 & 0 & \\
\hline $1000-1499$ & I & 2 & \\
\hline $1500-1999$ & 4 & 4 & \\
\hline $2000-2499$ & 14 & 11 & \\
\hline \multirow[t]{2}{*}{ All low birthweight } & $19(4.9 \%)$ & $17(4.3 \%)$ & \\
\hline & 365 & 373 & \\
\hline Missing data & (8) & (6) & \\
\hline All births & 392 & 396 & \\
\hline \multicolumn{4}{|l|}{ Gestation (weeks) } \\
\hline Mean (SD) & $39.6(1.7)$ & $39.6(1.7)$ & \\
\hline Preterm birth (<37 weeks) & $25(6.5 \%)$ & $17(4.6 \%)$ & OR (exact) I.I4 (0.56-2.34) \\
\hline \multicolumn{4}{|l|}{ Preterm birth } \\
\hline 20-27 weeks & 0 & 0 & \\
\hline 28-3I weeks & I & I & \\
\hline $32-36$ weeks & 24 & 16 & \\
\hline All preterm gestations & $25(6.5 \%)$ & $17(4.6 \%)$ & 'OR I.5I(0.77. 2.98) \\
\hline All with gestations $\geq 37$ weeks & 361 & 371 & \\
\hline Missing data & (6) & (6) & \\
\hline All gestations & 392 & 394 & \\
\hline
\end{tabular}

*All twins excluded

ing stillbirths and terminations of pregnancy for an identified malformation was 3.1\% [16].

An additional analysis prompted by the greater number of very preterm births in the intervention arm identified a shorter intervention to conception interval among very preterm births in that arm. Their mean interval was 82 weeks (SD 37) compared with a mean of 103 weeks (SD 63) for all births in the intervention arm, and 101 weeks (SD 64) for all births in the comparison arm.

\section{Discussion}

The PPIS trial was designed at the same time as a number of other very different pregnancy interventions designed to increase mean birth weight, and to reduce low birth weight and preterm birth through the provision of social support or enhanced nutrition [17-23]. None of the others implemented their intervention package before pregnancy but most aimed to recruit women relatively early in pregnancy. Four of these five trials and a recently reported additional trial [24] identified unexpected adverse outcomes, particularly extremely preterm births, or late terminations of pregnancy, i.e. findings similar to those in the PPIS trial. One factor which all of those trials had in common was that the intervention was provided by some- one who was not the usual provider of antenatal care. In the one trial where there were no such unexpected adverse outcomes the supportive intervention was provided at home by midwives, a pattern within usual maternity care in the UK, where the trial was carried out [17]. Midwives provided the intervention in the PPIS trial at home but this was not usual care in Australia.

Three hypotheses to explain the possible adverse outcomes of the PPIS trial came out of discussions with colleagues in Australia and Canada. The first was that the intervention itself might have heightened parental stress and anxiety about perinatal outcomes, with stress and anxiety contributing to very preterm birth $[25,26]$. The second was that there might have been an increased risk of conception at the extremes of the fertile period, giving rise to unplanned conception or less than ideal implantation, if women and their partners had given up their usual method of contraception for an alternative one. The shorter intervention to conception interval associated with the very preterm births in the intervention arm might be a marker for this risk factor. The third hypothesis was that if women and their partners took a very positive approach to the full intervention package it might have improved their overall health to a point where fetuses 
Table 4: Perinatal outcomes of the 2nd birth (post-intervention)

\begin{tabular}{|c|c|c|c|}
\hline & Intervention $\mathrm{N}=392$ & Comparison $\mathrm{N}=394$ & \\
\hline \multicolumn{4}{|l|}{ Birth interval (months) } \\
\hline Mead (SD) & $40.0(30)$ & $38.1(26)$ & $\mathrm{F} 0.89, \mathrm{p} 0.35$; unequal variance in birth interval \\
\hline Missing & $(2)$ & (I) & \\
\hline \multicolumn{4}{|l|}{ Birth weight } \\
\hline Mean (SD) & $3403(509)$ & $3500(504)$ & Difference $-97 \mathrm{~g}$ \\
\hline Missing data & (3) & (2) & \\
\hline Low birth weight (<2500 g) & $25 / 393$ & $14 / 394$ & OR (exact) I.85 [0.9I, 3.9I] \\
\hline Birth weight $<10^{\text {th }}$ percentile* & 40/378 (1 1\%) & $31 / 382(8 \%)$ & OR (exact) I.I4 [0.55, 2.38] \\
\hline \multicolumn{4}{|l|}{ Low birth weight } \\
\hline$<1000 \mathrm{~g}$ & 6 & 0 & \\
\hline $1000-1499$ & 3 & 0 & \\
\hline $1500-1999$ & 7 & 2 & \\
\hline $2000-2499$ & 9 & 12 & \\
\hline All with birth weight $(\geq 2,500 \mathrm{~g}$ & 367 & 380 & \\
\hline Missing data & (3) & $(2)$ & \\
\hline All births & 395 & 396 & \\
\hline \multicolumn{4}{|l|}{ Gestation } \\
\hline Mean (SD) & $39.3(2.2)$ & $39.5(1.5)$ & \\
\hline Preterm birth (<37 weeks) & $24(6 \%)$ & 17 (4\%) & OR (exact) I.44 $(0.73,2.9$ I) \\
\hline \multicolumn{4}{|l|}{ Preterm birth } \\
\hline $20-27$ weeks & 4 & 0 & \\
\hline 28-3I weeks & 6 & 1 & \\
\hline $32-36$ weeks & 14 & 16 & \\
\hline All with gestations $\geq 37$ weeks & 366 & 374 & \\
\hline Missing data & $(2)$ & (3) & \\
\hline All gestations & 392 & 394 & \\
\hline
\end{tabular}

*All twins excluded.

with a birth anomaly or with poor placentation were actually sustained in utero for a longer period of time, with a shift from miscarriage to very preterm birth.

Alternative explanations are that detailed discussions of family health increased perceptions of risk, or led to difficulties between the parents or difficulties with their families of origin. Recommendations to stop smoking, alcohol and over the counter drugs might have been another problematic piece of advice. It is also possible that the 'medicalisation' of such a human and family-focussed event as pregnancy and birth was in itself harmful. We could not totally rule out a contribution from selective participation in the study at the initial home visit: 65 women in the intervention arm, compared with 44 in standard care, opted out of the study. Overall, there were no significant differences in participation between the two arms.

Informed consent of participants was sought through the three-fold process outlined in the Methods: discussion of the trial by the MCHN, verbal agreement by the woman to have her details given to the PPIS midwife and subsequent contact by the midwife to make an appointment and follow-up with a visit. Consent of the Community Health
Centre, and the Maternal and Child Health service was based on a series of consultations held with each group, before the trial was implemented to describe the study and respond to queries, comments and criticisms. The Community Health Centre did not have a Human Research Ethics Committee and there was no equivalent body at that time in the then Health Commission of Victoria. When the project was awarded National Health and Medical Research Council research funding to complete the follow-up of second births (1992) we were required to provide written information about the study to all subsequent participants and to seek formal Ethics approval by the Board of the Community Health Centre. The Board co-opted an Ethics Committee Member from one of the nearby teaching hospitals to assist in this process.

Potential limitations of the intervention included the absence of advice to take periconceptional folate. In 1981-2 there was still marked disagreement about the benefits and risks of vitamins and folate before conception and in the first months of pregnancy. Publication of the proceedings of a workshop held in late 1982 for experts involved in recent or planned research on the prevention of neural tube defects, discussed the available evidence and its shortcom- 
ings and we were influenced by the evident uncertainty and disagreement [27]. By the time the four trials of periconceptional supplementation were published [28-31] recruitment to the PPIS trial was virtually complete.

Another potential limitation was the quality of the evidence on the effect of alcohol use before pregnancy. Several US papers had reported adverse effects on the fetus of even extremely low maternal consumption of alcohol, in early pregnancy or immediately prior to pregnancy, as well as effects of paternal alcohol use around the time of conception $[32,33]$. Despite the biological implausibility of some of these effects and the relatively small numbers of people in the studies we did advise stopping alcohol consumption before and during pregnancy. Contemporary population-based data on alcohol and tobacco use, collected in early pregnancy in another Australian state (Tasmania) did not show adverse effects of alcohol on fetal growth or preterm birth until maternal consumption was reported at more than two standard drinks a day [34], a level of drinking reported by $0.4 \%$ of Tasmanian women. Subsequent research in large cohorts has not confirmed the early US studies $[35,36]$.

Limitations of the trial included slow recruitment. It occurred at half the rate planned, extending the duration of the trial and making it harder to maintain local interest and Maternal and Child Health Nurses' enthusiasm. Another factor slowing recruitment was staff turnover [37]. A common work pattern at the time was moving to a new position after two years, to get a broad experience in community settings. Each new staff member needed a familiarization and training period: many were unfamiliar with randomised trials at the time of recruitment.

A greater limitation was the research team's lack of recognition that the women participating were of lower, rather than higher risk of adverse pregnancy outcomes. The decision to recruit women through existing services for mothers and infants failed to take into account the fact that women who had adverse outcomes in their first pregnancy (a perinatal death, an infant with a major congenital anomaly or a very preterm infant) would be underrepresented. Mothers whose infants had died would not be part of MCH services and mothers of infants requiring on-going care from hospitals or specialist services were likely to have been using those services, or visits to private paediatricians, for routine health advice and support as an alternative to their local MCHN. None of the first-born infants included in the PPIS trial was born before 30 weeks gestation.

More than $50 \%$ of participants moved house before the birth of their second child, making follow-up a much larger part of the midwives' role than originally planned
[38]. The average interval between the first and second births was a mean of 39 months compared with the predicted two years. This extended the time required for follow-up and made follow-up more difficult.

Other pre-pregnancy interventions are sparse. A recent systematic review of preconception interventions [39] found only one randomised trial [40] which used an opportunistic strategy, recruiting women who had a negative pregnancy test, explaining the trial, inviting participation, and randomising by tossing a coin. All participants were given a preconception risk survey. Although an average of over eight risks per woman were identified, and more than half the women made another visit to the service in the next year, there was no difference between intervention and usual care arms in the proportion of risks addressed. A recently reported trial recruited women who had given birth spontaneously before 34 weeks gestation, to be randomised four months after that birth to receive either oral azithromycin $1 \mathrm{~g}$ twice (4 days apart) plus $750 \mathrm{~g}$ of sustained-release metronidazole daily for seven days, or identical - appearing placebos, repeated every 4 months until the subsequent pregnancy. The intervention did not reduce subsequent preterm birth with these authors also concluding that the intervention might be associated with a shorter gestational age and lower birth weight [41].

The PPIS study strengths are that it remains the only completed trial of a broad pre-pregnancy intervention. It demonstrated that it was feasible to test a pre-pregnancy intervention using a 'gold standard' design within socially disadvantaged communities, including women on low incomes and culturally diverse women, incorporating the intervention into an existing population-wide service. It provided a model for joint action between four community health services. It also identified issues relevant to the planning of future trials. Data on the high proportion of participants who turned out to be ineligible or lost to the study are likely to be relevant to other population based pre-pregnancy interventions.

\section{Conclusion}

Despite wide-ranging support for pre-pregnancy interventions to improve maternal and perinatal outcomes [42] none of the published trials so far, nor this trial, has identified beneficial effects.

\section{Competing interests}

The author(s) declare that they have no competing interests.

\section{Authors' contributions}

JL designed the study, carried out the data analysis and drafted the paper. LD managed the data collection, fol- 
Table 5: Reporting details for randomised trials

\begin{tabular}{|c|c|c|c|}
\hline PAPER SECTION And topic & Item & Description & Reported on Page \# \\
\hline TITLE \& ABSTRACT & I & $\begin{array}{l}\text { How participants were allocated to interventions (e.g., "random allocation", } \\
\text { "randomized", or "randomly assigned"). }\end{array}$ & 4 \\
\hline INTRODUCTION Background & 2 & Scientific background and explanation of rationale. & 3 \\
\hline METHODS Participants & 3 & $\begin{array}{l}\text { Eligibility criteria for participants and the settings and locations where the data were } \\
\text { collected. }\end{array}$ & $3-4$ \\
\hline Interventions & 4 & $\begin{array}{l}\text { Precise details of the interventions intended for each group and how and when they } \\
\text { were actually administered. }\end{array}$ & $4-5$ \\
\hline Objectives & 5 & Specific objectives and hypotheses. & 4 \\
\hline Outcomes & 6 & $\begin{array}{l}\text { Clearly defined primary and secondary outcome measures and, when applicable, any } \\
\text { methods used to enhance the quality of measurements (e.g., multiple observations, } \\
\text { training of assessors). }\end{array}$ & 5 \\
\hline Sample size & 7 & $\begin{array}{l}\text { How sample size was determined and, when applicable, explanation of any interim } \\
\text { analyses and stopping rules. }\end{array}$ & 5 \\
\hline Randomization - Sequence generation & 8 & $\begin{array}{l}\text { Method used to generate the random allocation sequence, including details of any } \\
\text { restrictions (e.g., blocking, stratification) }\end{array}$ & $4-5$ \\
\hline Randomization - Allocation concealment & 9 & $\begin{array}{l}\text { Method used to implement the random allocation sequence (e.g., numbered containers } \\
\text { or central telephone), clarifying whether the sequence was concealed until } \\
\text { interventions were assigned. }\end{array}$ & 4 \\
\hline Randomization - Implementation & 10 & $\begin{array}{l}\text { Who generated the allocation sequence, who enrolled participants, and who assigned } \\
\text { participants to their groups. }\end{array}$ & $4-5$ \\
\hline Blinding (masking) & II & $\begin{array}{l}\text { Whether or not participants, those administering the interventions, and those assessing } \\
\text { the outcomes were blinded to group assignment. When relevant, how the success of } \\
\text { blinding was evaluated. }\end{array}$ & $\mathrm{n} / \mathrm{a}$ \\
\hline Statistical methods & 12 & $\begin{array}{l}\text { Statistical methods used to compare groups for primary outcome(s); Methods for } \\
\text { additional analyses, such as subgroup analyses and adjusted analyses. }\end{array}$ & 6 \\
\hline RESULTS Participant flow & 13 & $\begin{array}{l}\text { Flow of participants through each stage (a diagram is strongly recommended). } \\
\text { Specifically, for each group report the numbers of participants randomly assigned, } \\
\text { receiving intended treatment, completing the study protocol, and analyzed for the } \\
\text { primary outcome. Describe protocol deviations from study as planned, together with } \\
\text { reasons. n/a }\end{array}$ & 7, 22, Table I \\
\hline Recruitment & 14 & Dates defining the periods of recruitment and follow-up. & 8 \\
\hline Baseline data & 15 & Baseline demographic and clinical characteristics of each group. & 6, Table 2 \\
\hline Numbers analyzed & 16 & $\begin{array}{l}\text { Number of participants (denominator) in each group included in each analysis and } \\
\text { whether the analysis was by "intention-to-treat". State the results in absolute numbers } \\
\text { when feasible (e.g., 10/20, not 50\%). }\end{array}$ & 392 and 394, I-T-T \\
\hline Outcomes and estimation & 17 & $\begin{array}{l}\text { For each primary and secondary outcome, a summary of results for each group, and the } \\
\text { estimated effect size and its precision (e.g., } 95 \% \text { confidence interval). }\end{array}$ & Tables 3 and 4 \\
\hline Ancillary analyses & 18 & $\begin{array}{l}\text { Address multiplicity by reporting any other analyses performed, including subgroup } \\
\text { analyses and adjusted analyses, indicating those pre-specified and those exploratory. }\end{array}$ & $\mathrm{n} / \mathrm{a}$ \\
\hline Adverse events & 19 & All important adverse events or side effects in each intervention group. & 8 \\
\hline DISCUSSION Interpretation & 20 & $\begin{array}{l}\text { Interpretation of the results, taking into account study hypotheses, sources of potential } \\
\text { bias or imprecision and the dangers associated with multiplicity of analyses and } \\
\text { outcomes. }\end{array}$ & $8-10$ \\
\hline Generalizability & 21 & Generalizability (external validity) of the trial findings. & $9-10$ \\
\hline Overall evidence & 22 & General interpretation of the results in the context of current evidence. & $9-10$ \\
\hline
\end{tabular}


lowed the participants, and contributed to the paper. Both authors read and approved the final manuscript.

\section{Acknowledgements}

This study was developed as part of a new health program offering prepregnancy advice and referral in the established Richmond Community Health Centre (RCHC). Professor Carl Wood and Emeritus Professor William Walters initiated the program with the support of the RCHC Director, and Drs Syd Allen and Norman Morris worked with the pre-pregnancy midwives in their local secondary school education program.

We are very grateful to the midwives who carried out the intervention: Prue Plovanic, Cindy Trickett, Helen Walsh, Rosemary Burrell, and Margaret Jenkins. We thank all the Maternal and Child Health Nurses who recruited women to the study: Christine Barclamb/Clarke, Muriel Baird, Jenny Bock, Mary Dowling, Andrea Devine/Heffernan, Nola Fleming, Carolyn Hutchins, Judy Lawson, Claire Lovat, Rosemary McCormick, Suzanne Mott, Jane Pease, Reay Pressor, Allanna Sharp, Faye Stanesby, Paula Walsh, jill Teschendorf and Brenda Wright.

We also thank the municipalities who supported their MCHNs' participation: Burnley, North Fitzroy, North Richmond, Prahran, South Yarra and Windsor.

The trial was supported by practical contributions from participating municipalities, the Central Interpreter Service, the Richmond Community Health Centre and Monash University Department of Obstetrics and Gynaecology. We are grateful for a Research and Development Grant from the National Health and Medical Research Council

\section{References}

I. Wynn M, Wynn A: Prevention of handicap and the health of women. London: Routledge \& Kegan Paul; 1979:43-63.

2. Lumley J, Astbury J: Advice for pregnancy. In Effective care in pregnancy and childbirth Edited by: Chalmers I, Enkin M, Keirse M. Oxford, Oxford University Press; 1982:236-254.

3. Kohner N, Health Education Council: Pregnancy book. A guide to becoming pregnant, being pregnant and caring for your newborn baby. London: Health Education Council; 1984.

4. US Academy of Sciences, Committee to Study the Prevention of Low Birth Weight, Division of Health Promotion and Disease Prevention, Institute of Medicine. In Preventing low birthweight Washington, DC, National Academy Press; 1985: I-3. I518

5. Lumley J, Allen PS, Plovanic P, Wood C, Walters W: The prepregnancy clinic. Brit Med J 1980, 28 I:6 19. (Letter)

6. Chamberlain G, Lumley J, (eds): Pre-pregnancy care. In A manual for practice John Wiley \& Sons, Chichester; 1986.

7. Goldenberg RL, Culhane JF: Prepregnancy health status and the risk of preterm delivery. Arch Pediatr Adolesc Med 2005, I 59:89-90.

8. Department of Human Services, Victoria: Maternal and Child Health Program, Annual Report 1995-6. Melbourne, Department of Human Services; 1997.

9. Alderson M: An introduction to epidemiology. London and Basingstoke, The Macmillan Press; 1976:I I3, I80.

10. Gates $S$, Brocklehurst $P$ : How should randomised trials including multiple pregnancies be analysed? BJOG 2004, I I I:2 I3-9.

11. Kramer MS, Platt RW, Wen SW, Joseph KS, Allen A, Abrahamowicz $\mathrm{M}$, Blondel B, Bréart G: A new and improved population-based Canadian reference for birthweight for gestational age. Pediatrics 200I, 108:e35.

12. Dean AG, Dean JA, Burton AH, Docker RC: Epi Info version 5: a word processing, database and statistics program for epidemiology on microcomputers. USD, Incorporated, Stone Mountain Georgia 1990.

13. Stata Corporation STATA 8.0 Statistics/Data Analysis, 2003. Stata Corporation: college Station, Texas.
14. Congalton AA: Status and prestige in Australia. Melbourne: Cheshire; 1969.

15. Perinatal Data Collection Unit, Victoria: Births In Victoria 198392. Melbourne: The Consultative Council on Obstetric and Paediatric Mortality and Morbidity, Victoria; 1994. Table 5.2

16. Perinatal Data Collection Unit, Victoria: Congenital malformations in Victoria, 1 983-94. The Consultative Council on Obstetric and Paediatric Mortality and Morbidity, Victoria; 1996: I I.

17. Oakley A, Rajan L, Grant A: Social support and pregnancy outcome. Br J Obstet Gynaecol 1990, 97:155-162.

18. Spencer B, Thomas H, Morris J: A randomized controlled trial of the provision of a social support service during pregnancy: the South Manchester Family Worker Project. Br J Obstet Gynaecol 1989, 96:28I-8.

19. Bryce R: Support in pregnancy. Int J Technol Assess Health Care I991, 7:478-84

20. Bryce R, Stanley FJ, Garner JB: Randomized controlled trial of antenatal social support to prevent preterm birth. BrJ Obstet Gynaecol 1991, 98:1001-8.

21. Rush D, Stein Z, Susser M: A randomized controlled trial of prenatal nutritional supplementation in New York City. Pediatrics 1980, 65(4):683-97.

22. Kafatos AG, Tsitoura S, Pantelakis SN, Doxiadis SA: Maternal and infant health education in a rural Greek community. Hygie 1991, I0(I):32-7.

23. Kafatos AG, Vlackonikolis JG, Cadrington CA: Nutrition during pregnancy: the effect of an educational intervention program in Greece. Am J Clin Nutr 1989, 50:970-9.

24. Osrin D, Viadya A, Shrestha Y, et al.: Effects of antenatal multiple micronutrient supplementation on birthweight and gestational age duration in Nepal: double-blind randomised controlled trial. Lancet 2005, 365(9463):916-7.

25. Dole N, Savitz DA, Hertz-Picciotto I, Siega-Riz AM, McMahon MJ, Buekens P: Maternal stress and preterm birth. Am J Epidemiol 2003, I 57(I): 14-24.

26. Ruiz RJ, Fullerton J, Dudley DJ: The interrelationship of maternal stress, endocrine factors, and inflammation on gestational length. Obstet Gynecol Surv 2003, 58(6):415-28.

27. Wald N: Possible prevention of neural tube defects by vitamin supplementation. Appendix III. In Prevention of spina bifida and other neural tube defects Edited by: Dobbing J. London: Academic Press; 1983:23I-239.

28. Czeizel AE, Dudás I: Prevention of first occurrence of neural tube defects by periconceptional vitamin supplementation. New Engl J med 1992, 327: | 832-35.

29. Kirke PN, Daly LE, Elwood JH, for the Irish Vitamin Study Group: A randomised trial of low dose folic acid tp prevent neural tube defects. Arch Dis Child 1992, 67:1442-6.

30. MRC Vitamin Study Group: Prevention of neural tube defects: results of the Medical Research Council Vitamin Study. Lancet |99|, 338:|3|-7.

3I. Laurence KM, James N, Miller MH, Tennnant BG, Campbell H: Double-blind randomised controlled trial of folate treatment before conception to prevent recurrences of neural tube defects. Br Med J 198I, 282:1509-II.

32. Little RE, Sing CF: Father's drinking and infant birth weight: report of an association. Teratology 1987, 36:59-65.

33. Little RE, Asker RL, Sampson PD, Renwick JH: Fetal growth and moderate drinking in early pregnancy. Am J Epidemiol 1986, 123:270-8.

34. Lumley J, Newman NM, Curran JT: Cigarette smoking, alcohol consumption and fetal outcome in Tasmania 198I-2. Aust NZ J Obstet Gynaecol 1985, 25:33-40.

35. Passaro KT, Little RE, Savitz DA, Noss J: Effect of paternal alcohol consumption before conception on infant birth weight. ALSPAC Study Team. Teratology 1998, 57:294-301.

36. Passaro KT, Little RE, Savitz D, Noss J: Effect of maternal drinking before conception and in early pregnancy on infant birthweight. ALSPAC Study Team. Avon Longitudinal Study of Pregnancy and Childhood. Epidemiology 1996, 7:377-83.

37. Jackson M, Berman N, Huber M, Snetselaar L, Granek I, Boe K, Milas C, Spivak J. Chlebowski RT: Research staff turnover and participant adherence in the Women's Health Initiative. Controlled Clinical Trials 2003, 24:422-35.

38. Donohue L: Tracing lost research participants. Aust J Adv Nursing 1995, 12:6-10. 
39. Korenbrot CC, Steinberg A, Bender C, Newberry S: Preconception care: a systematic review. Maternal and Child Health J 2002, 6(2):75-88.

40. Jack BW, Culpepper L, Babcock J, Kogan MD, Weissmiller D: Addressing preconception risks identified at the time of a negative pregnancy test: a randomised trial. J Fam Pract 1998, 47(I):33-8.

4I. Andrews WW, Goldenberg RL, Hauth JC, Cliver SP, Copper R, Connor $M$ : Inter-conceptional antibiotics to prevent spontaneous preterm birth: a randomized clinical trial. Am J Obstet Gynecol 2006, 194:617-23.

42. Johnson K, Posner SF, Biermann J, Cordero JF, Atrash HK, Parker CS, Boulet S, Curtis MG, CDC/ATSDR Preconception Care Work Group and the Select Panel on Preconception Care: Recommendations to Improve Preconception Health and Health Care - United States. MMWR 55(RR06): I-23. April 2I, 2006

\section{Pre-publication history}

The pre-publication history for this paper can be accessed here:

http://www.biomedcentral.com/1471-2458/6/299/pre pub

Publish with Bio Med Central and every scientist can read your work free of charge

"BioMed Central will be the most significant development for disseminating the results of biomedical research in our lifetime. "

Sir Paul Nurse, Cancer Research UK

Your research papers will be:

- available free of charge to the entire biomedical community

- peer reviewed and published immediately upon acceptance

- cited in PubMed and archived on PubMed Central

- yours - you keep the copyright

Submit your manuscript here:

http://www.biomedcentral.com/info/publishing_adv.asp
BioMedcentral 